\title{
ESTUDOS DE UM BANCO DE SEMENTES NO SOLO DE UM FRAGMENTO FLORESTAL COM Araucaria angustifolia NO ESTADO DO PARANÁ
}

\author{
Marcelo Lima de Souza ${ }^{1}$, Antônio Carlos Nogueira ${ }^{2}$, Renato Luiz Grisi Macedo ${ }^{3}$, \\ Carlos Roberto Sanquetta ${ }^{4}$, Nelson Venturin ${ }^{3}$
}

${ }^{1}$ Eng. Agrônomo, M.Sc, UFLA, Lavras, MG, Brasil - marcelo.souza2007@yahoo.com.br ${ }^{2}$ Eng. Florestal, Dr., Depto. de Ciências Florestais, UFPR, Curitiba, PR, Brasil - nogueira@ufpr.br ${ }^{3}$ Eng. Florestal, Dr., Depto. de Ciências Florestais, UFLA, Lavras, MG, Brasil - rlgrisi@ufla.br; venturim@ufla.br ${ }^{4}$ Eng. Florestal, Dr., Depto. de Ciências Florestais, UFPR, Curitiba, PR, Brasil - sanquetta@ufpr.br

Recebido para publicação: 17/11/2008 - Aceito para publicação: 22/03/2010

\begin{abstract}
Resumo
O objetivo do presente trabalho foi estudar o banco de sementes no solo de um fragmento florestal com Araucaria angustifolia (Bert.) O. Ktze. no estado do Paraná. Para isso, investigou-se a distribuição vertical das sementes, a influência do sombreamento sobre a emergência das plântulas, sua identificação e quantificação. A distribuição vertical de sementes em quatro camadas foi analisada através da identificação e quantificação das plântulas emergentes em casa de vegetação, levando em consideração o nível de sombreamento. Os dados referentes ao banco de sementes foram obtidos no período de 210 dias, por meio de identificação botânica e contagens semanais das plântulas germinadas das quatro profundidades de solo em quatro parcelas experimentais. As amostras foram colocadas para germinar sob 0 e $50 \%$ de sombreamento em casa de vegetação. Os resultados obtidos no estudo de banco de sementes permitiram as seguintes conclusões: o banco de sementes parece ser pobre em espécies arbóreas e abundante em espécies herbáceas; o banco de sementes das espécies arbóreas foi maior na segunda camada; ocorreu maior germinação sob $0 \%$ de sombreamento. Provavelmente, a estratégia de regeneração da maioria das espécies presentes nessa área de estudo parece não ser pelo banco de sementes no solo.
\end{abstract}

Palavras-chave: Banco de sementes no solo; Araucaria angustifolia; fragmento florestal.

\begin{abstract}
Soil seed bank analysis in a forest fragment with Araucaria angustifolia, State of Parana. A research on soil seed bank had been developed in an Araucaria angustifolia (Bert.) O. Ktze. forest fragment in the State of Paraná. It had surveyed vertical distribution of seeds within the soil and shadow influence on seedling emergence, besides the improvement of their identification and quantity measuring. Vertical distribution of seeds in four soil layers had been analyzed by identification and quantification of germinated seedlings in greenhouse, with full light or 50\% shaded conditions. Data related to seedlings of trees, weeds, grasses and lianas were calculated separately in weekly intervals during a 210-day period. Results suggested that the soil seed bank in this forest was poor in relation to tree species, in diversity as far as density. On the other hand, seeds of grasses and weeds decreased along vertical soil profile, and forest tree species tended to abundance in the 5-10 cm layer. Germination was higher with full light than in 50\% shaded conditions. Probably, regeneration strategy for most species in this focused area doesn't seem to be soil seed bank.
\end{abstract}

Keywords: Soil seed bank; Araucaria angustifolia; forest fragment.

\section{INTRODUÇÃO}

Atualmente, a silvicultura, através de suas diferentes linhas de atuação, tem-se preocupado com o conhecimento, a conservação e o aproveitamento racional das florestas naturais. Dessa forma, é evidente que a conservação das florestas naturais somente poderá acontecer se forem estudadas formas de 
aproveitamento sustentado, baseadas no conhecimento da ecologia das espécies e de suas inter-relações com os demais fatores ambientais (LAMPRECHT, 1990).

Diante da necessidade de estudos sobre a dinâmica da regeneração natural em fragmentos florestais, esta pesquisa objetivou estudar o banco de sementes no solo de um fragmento florestal com Araucaria angustifolia (Bert.) O. Ktze., visando investigar a distribuição vertical das sementes no solo, a influência do sombreamento sobre a emergência das plântulas, sua identificação e quantificação. Além disso, os experimentos foram projetados a partir da hipótese de que a estratégia de regeneração natural da maioria das espécies deste fragmento florestal com Araucaria angustifolia ocorre através da formação de banco de sementes no solo.

\section{REVISÃO DE LITERATURA}

\section{Dispersão de sementes}

A composição do banco de sementes no solo é afetada tanto pelos tipos de dispersão das espécies presentes na área como daquelas presentes em áreas adjacentes. Dessa forma, a seleção natural beneficiou as espécies que possuíam características biológicas que as colocassem em vantagem sobre as outras, tais como meios eficientes de dispersão de sementes, dormência e rápido crescimento (YOUNG et al., 1987).

A dispersão de sementes é um evento que ocorre na natureza cuja finalidade é a colocação do número máximo de sementes em diversos lugares. Esse processo pode ser conceituado como o movimento de um diásporo, de uma planta de um local para outro, incluindo nessa trajetória os agentes dispersores (dispersão zoocórica) (BERG, 1983). Conforme Gentry (1983), a distribuição das plantas na floresta natural depende, em grande parte, do comportamento dos animais que efetuam a dispersão, principalmente daqueles que se alimentam de frutos.

Segundo Dantas (1989), o banco de sementes no solo e a dispersão de sementes exercem importante papel em qualquer processo de sucessão secundária.

\section{Formação do banco de sementes}

O banco de sementes no solo é composto pelas sementes viáveis e que, através de sua dormência, permanecem presentes na superfície ou no interior do solo de determinada área (BASKIN; BASKIN, 1989).

As sementes que entram na composição do banco de sementes no solo são introduzidas através da chuva de sementes, por intermédio da dispersão de sementes de espécies presentes na área ou de áreas circunvizinhas.

O entendimento do fluxo de sementes entrando através da chuva de sementes (sementes recentemente dispersas) e saindo através da predação, germinação e deterioração/morte de sementes de uma determinada área é fundamental em estudos sobre banco de sementes no solo.

Assim, durante a chuva de sementes, podem ocorrer dois eventos: parte das sementes pode ser predada antes mesmo de participar do banco de sementes no solo, e outra parte provavelmente irá formar o banco de sementes.

A saída de sementes do banco pode ocorrer por meio de um estímulo, desencadeando a quebra de dormência das sementes e posterior germinação, pela deterioração e pela morte através da perda do poder germinativo e pela predação exercida pelas populações de fauna presentes na área (FENNER, 1985).

Esse fluxo de sementes, entrando e saindo de uma determinada área, determina a quantidade potencial que caracteriza o banco de sementes no solo.

O balanço entre entradas e saídas determina um estoque acumulado que varia em função do tipo de sementes. Quando esse estoque acumulado é composto por sementes viáveis no solo por um limitado período de tempo, chama-se banco de sementes transitório. Ao contrário, quando as sementes viáveis no solo permanecem por um período de tempo suficientemente longo, denomina-se banco de sementes persistente (FENNER, 1985).

De acordo com Budowski (1965), esse processo envolve a substituição de uma comunidade de planta por outra. A sucessão se inicia com as espécies herbáceas e arbóreas, cujas sementes são armazenadas no solo, formando, assim, o banco de sementes no solo. As sementes são depositadas no solo, ao longo do tempo, e aí permanecem viáveis por longos anos, até que as condições ambientais sejam propícias à germinação para florestas tropicais: amazônica, com araucária, atlântica. 


\section{Germinação e dormência}

Após a dispersão, parte das sementes passa por um período de dormência. Dependendo da espécie e das condições prevalecentes, a dormência pode permanecer por pouco tempo ou muitas décadas.

As sementes dormentes requerem um estímulo ambiental para quebrar a dormência, como flutuações de temperatura e exposição à luz, além de outros fatores.

Segundo Abdulhadi (1991), a luz e a temperatura poderão estimular sementes dormentes e longevas enterradas no solo a germinaram, particularmente as sementes de espécies pioneiras, que são mais sensíveis a ambos os fatores.

Rico-Gray; Garcia-Franco (1992) observaram em uma área perturbada pelo fogo que sementes de algumas espécies herbáceas e de arbustos eram estimuladas a germinar.

A dormência e a longevidade são dois mecanismos que capacitam as plantas a sincronizarem o seu desenvolvimento com o ambiente. A dormência é caracterizada pelo período em que o crescimento é reduzido ou suspenso, a fim de evitar as condições adversas do meio (METIVIER, 1986). A longevidade está relacionada com a perda do poder germinativo.

\section{Profundidade do banco de sementes no solo}

O modelo de distribuição vertical de sementes no solo é relativamente pouco estudado. Isso, provavelmente, está associado ao fato de que determinar a presença do banco de sementes em diferentes profundidades não é uma tarefa muito fácil.

Para Young (1985), as sementes enterradas profundamente apresentam menor probabilidade de germinar do que aquelas dispostas na superfície do solo. Esse mesmo autor constatou que a contribuição das sementes enterradas mais profundamente, para a recolonização de uma área, depende da movimentação do solo e/ou da semente.

Ele relata que, quanto maior a quantidade de organismos vivos no solo, maior será a profundidade de distribuição de sementes, principalmente em solo de florestas naturais.

Segundo Roberts; Feast (1972), sementes enterradas a maiores profundidades no solo tendem a permanecer dormentes por um longo período, e poucas delas obtêm sucesso na formação de plântulas, devido às condições de umidade e temperatura associadas à exaustão dos nutrientes.

Cheke et al. (1979) encontraram sementes viáveis de árvores até $20 \mathrm{~cm}$ de profundidade no solo de uma floresta tropical da Tailândia.

Holthuijzen; Boerboom (1982), ao analisarem os perfis de solo de $20 \mathrm{~cm}$ de profundidade, detectaram que o conteúdo de sementes viáveis de Cecropia diminuía abruptamente com a profundidade.

\section{MATERIAL E MÉTODOS}

O presente estudo foi conduzido na Estação Experimental da Universidade Federal do Paraná, situada no município de São João do Triunfo, na região centro-sul do estado do Paraná, a qual possui uma área de cerca de 32 hectares, distante $130 \mathrm{~km}$ de Curitiba.

\section{Caracterização edafoclimática}

Conforme a classificação climática de Köppen, a região apresenta um clima temperado sempre úmido, do tipo $\mathrm{Cfb}$, caracterizado por uma temperatura inferior a $22{ }^{\circ} \mathrm{C}$ durante o mês mais quente (MAACK, 1968).

De acordo com Longhi (1980), o solo da área de estudo é do tipo podzólico vermelho-amarelo distrófico, com uma pequena proporção com solo do tipo Cambissolo distrófico álico.

A vegetação da área de estudo é a Floresta Ombrófila Mista (ou Floresta com Araucária), fazendo parte dos domínios da Floresta Ombrófila Mista Montana do Primeiro Planalto Paranaense (VELOSO, 1991).

\section{Implantação das parcelas e coleta de solos}

$\mathrm{Na}$ área de estudo, foram implantadas quatro parcelas de 1 hectare cada uma. Em cada parcela foram amostradas nove subparcelas (unidades amostrais - u.a.) com dimensão de $20 \mathrm{x} 20 \mathrm{~cm}$ de profundidade. Em cada subparcela foram amostradas 4 camadas de solo, com dimensões de $20 \times 20 \times 5 \mathrm{~cm}$. As coletas de solos foram realizadas no final de março. 


\section{Descrição das parcelas}

Parcela I: área com grande ocorrência de espécies folhosas no dossel e presença esparsa de Araucaria angustifolia (Bert.) O. Ktze;

Parcela II: área com ampla dominância de Araucaria angustifolia (Bert.) O. Ktze. no dossel;

Parcela III: local afetado por incêndio, com ocorrência de espécies pioneiras típicas (Mimosa scabrella Benth. (bracatinga);

Parcela IV: local onde houve lavoura no passado e influência fluvial.

\section{Coleta de dados}

Na casa de vegetação localizada no Centro de Ciências Agrárias da Universidade Federal do Paraná, as amostras de solo permaneceram por um período de 210 dias sob duas condições de luminosidade (com sombrite $50 \%$ e sem sombrite). Após esse período, foi feita a coleta e contagem das plântulas emergentes. Com os dados numéricos discretos da contagem do número total de plântulas emergentes, utilizou-se técnica de estatística descritiva para proceder aos cálculos por unidade amostral por $\mathrm{m}^{2}$ e hectare.

Uma parte das amostras de solo foi colocada no germinador do Laboratório de Sementes da referida instituição, a uma temperatura de $25{ }^{\circ} \mathrm{C}$, durante 120 dias. Durante esse período de observação nessa condição, somente houve germinação de gramíneas.

Simultaneamente, foi realizada uma outra coleta de solos. Para esse novo material, foi usada uma técnica de peneiragem do solo, na tentativa de quantificar e qualificar as sementes nele presentes.

O material proveniente da peneiragem foi levado para o Laboratório de Dendrologia do Curso de Engenharia Florestal da Universidade Federal do Paraná, para identificação com lupa.

\section{RESULTADOS}

\section{Espécies presentes no banco de sementes no solo}

Após a identificação das espécies emergentes em casa de vegetação, foi feita uma avaliação do banco de sementes no solo. A tabela 1 apresenta as 16 famílias e as 21 espécies do banco de sementes no solo encontradas nas quatro parcelas da Estação Experimental de São João do Triunfo. Também constam quatro espécies identificadas apenas em nível de família. São registradas espécie, nome vulgar, família, hábito e ocorrência de cada indivíduo nas respectivas parcelas amostrais.

Tabela 1. Espécies encontradas no banco de sementes no solo nas quatro parcelas experimentais.

Table 1. Species found in the soil seed bank in the four plots.

\begin{tabular}{|c|c|c|c|c|c|c|c|}
\hline \multirow{2}{*}{ Espécie } & \multirow{2}{*}{ Nome vulgar } & \multirow{2}{*}{ Família } & \multirow{2}{*}{ Hábito ${ }^{*}$} & \multicolumn{4}{|c|}{ Ocor.parc. } \\
\hline & & & & 1 & 2 & 3 & 4 \\
\hline Aegiphila sellowiana Cham. & pau-de-tamanco & Verbenaceae & arbórea & $\mathrm{x}$ & & & \\
\hline Begonia cf. cucullata Willd. & begônia & Begoniaceae & herbácea & & & & $\mathrm{x}$ \\
\hline Borreria alata D.C. & poaia-do-campo & Rubiaceae & herbácea & $\mathrm{x}$ & $\mathrm{x}$ & & $\mathrm{x}$ \\
\hline Cyperus sp. & tiririca & Cyperaceae & gramínea & $\mathrm{x}$ & $\mathrm{x}$ & $\mathrm{x}$ & $\mathrm{x}$ \\
\hline Gnaphalium sp. & macela & Asteraceae & herbácea & $\mathrm{x}$ & $\mathrm{x}$ & $\mathrm{x}$ & $\mathrm{x}$ \\
\hline Hydrocotyle cf. leucocephala Cham. e Sc. & capitão & Apiaceae & herbácea & $\mathrm{x}$ & & $\mathrm{x}$ & $\mathrm{x}$ \\
\hline Mimosa scabrella Benth. & bracatinga & Mimosaceae & arbórea & $\mathrm{x}$ & $\mathrm{x}$ & $\mathrm{x}$ & $\mathrm{x}$ \\
\hline Mikania sp. & cipó-cabeludo & Asteraceae & cipó & & & & $\mathrm{x}$ \\
\hline Myrsine ferruginea Sprengel & capororoca & Myrsinaceae & arbórea & $\mathrm{x}$ & & & $\mathrm{x}$ \\
\hline Panicum sp. & capim-sempre-verde & Poaceae & gramínea & $\mathrm{x}$ & & $\mathrm{x}$ & $\mathrm{x}$ \\
\hline Pavonia sp. & guanxuma & Malvaceae & herbácea & & & & $\mathrm{x}$ \\
\hline Phyllanthus niruri L. & quebra-pedra & Euphorbiaceae & herbácea & $\mathrm{x}$ & $\mathrm{x}$ & $\mathrm{x}$ & $\mathrm{x}$ \\
\hline Phytolacca thyrsiflora Fenzl ex J.A. Sc. M. & caruru & Phytolaccaceae & herbácea & $\mathrm{x}$ & $\mathrm{x}$ & $\mathrm{x}$ & $\mathrm{x}$ \\
\hline Senecio brasiliensis Less. Linnaea & cravo-do-campo & Asteraceae & herbácea & $\mathrm{x}$ & $\mathrm{x}$ & $\mathrm{x}$ & $\mathrm{x}$ \\
\hline Solanum sp. & joá-ti & Solanaceae & herbácea & $\mathrm{x}$ & $\mathrm{x}$ & $\mathrm{x}$ & $\mathrm{x}$ \\
\hline Sonchus asper (L.) Hill. & serralha & Asteraceae & herbácea & & & $\mathrm{x}$ & \\
\hline Sonchus ciliatus Lam. & serralha-lisa & Solanaceae & herbácea & & & & $\mathrm{x}$ \\
\hline Spigelia pusilla Mart. & erva-lombrigueira & Loganiaceae & herbácea & & $\mathrm{x}$ & & \\
\hline
\end{tabular}




\begin{tabular}{|c|c|c|c|c|c|c|c|}
\hline Tibouchina clinopodifolia (DC.) Cogn. & cipó & Melastomataceae & cipó & $\mathrm{x}$ & & & $\mathrm{x}$ \\
\hline Tragia volubilis $\mathrm{L}$. & cipó & Euphorbiaceae & cipó & & $\mathrm{x}$ & $\mathrm{x}$ & $\mathrm{x}$ \\
\hline Zanthoxyllum rhoifolium Lam. & juvevê & Rutaceae & arbóreo & $\mathrm{x}$ & $\mathrm{x}$ & $\mathrm{x}$ & $\mathrm{x}$ \\
\hline Não identificada 1 & grama-doce & Poaceae & gramínea & $\mathrm{x}$ & & $\mathrm{x}$ & $\mathrm{x}$ \\
\hline Não identificada 2 & capim-da-roça & Poaceae & gramínea & $\mathrm{x}$ & $\mathrm{x}$ & $\mathrm{x}$ & $\mathrm{x}$ \\
\hline Não identificada 3 & capim-de-pasto & Poaceae & gramínea & & & $\mathrm{x}$ & $\mathrm{x}$ \\
\hline Não identificada 4 & não identificada & Asteraceae & & & $\mathrm{x}$ & $\mathrm{x}$ & $\mathrm{x}$ \\
\hline
\end{tabular}

* Classificação segundo LORENZI (1982).

Das 16 famílias, 4 correspondem a espécies arbóreas, 10 a espécies herbáceas e cipós ou lianas e 2 correspondem a gramíneas. As espécies Mimosa scabrella Benth., vulgarmente conhecida como bracatinga, e o juvevê, Zanthoxyllum rhoifolium Lam., ocorreram em todas as parcelas do experimento. Aegiphila sellowiana Cham. (pau-de-tamanco) ocorreu somente na parcela 1. A capororoca, Myrsine ferruginea Sprengel, ocorreu nas parcelas 1 e 4.

\section{Distribuição vertical do banco de sementes no solo}

A tabela 2 mostra o número médio de sementes germinadas nas quatro profundidades das quatro parcelas amostradas. O Cyperus sp. apresentou a maior média, com 725.926 indivíduos por hectare. Em seguida, tem-se a Pavonia sp., com 420.370 indivíduos. O juvevê, Zanthoxyllum rhoifolium Lam., apareceu em décimo terceiro lugar, com uma população de 33.333 indivíduos por hectare. Em décimo sexto lugar encontra-se a bracatinga, Mimosa scabrellla Benth., com uma população de 18.519 plantas por hectare. Em seguida, tem-se a capororoca, Myrsine ferruginea Sprengel, com 12.963 plantas. Por último, tem-se o pau-de-tamanco, Aegiphila sellowiana Cham., com 1.852 indivíduos por hectare.

Tabela 2. Número médio de sementes germinadas ( $\mathrm{n} \% \mathrm{ha}$ ) nas quatro profundidades das quatro parcelas.

Table 2. Average number of seeds germinated $\left(\mathrm{n}^{\circ} / \mathrm{ha}\right)$ in the four depths of the four plots.

\begin{tabular}{|c|c|c|c|c|c|c|}
\hline \multirow{2}{*}{ Espécie } & \multicolumn{6}{|c|}{ Profundidades $(\mathrm{cm})$} \\
\hline & $0-5$ & $5-10$ & 10-15 & 15-20 & Total & Média \\
\hline Cyperus sp. & 1511111 & 629630 & 511111 & 251852 & 903704 & 725926 \\
\hline Pavonia sp. & 777778 & 414815 & 266667 & 222222 & 1681481 & 420370 \\
\hline Não identificada 2 & 1133333 & 229630 & 44444 & 22222 & 1429630 & 357407 \\
\hline Gnaphalium sp. & 614815 & 81481 & 37037 & & 733333 & 183333 \\
\hline Senecio brasiliensis Less. Linnaea & 451852 & 22222 & 7407 & & 481481 & 120370 \\
\hline Borreria alata DC. & 244444 & 140741 & 44444 & 14815 & 444444 & 111111 \\
\hline Não identificada 1 & 214815 & 37037 & 29630 & 51852 & 333333 & 83333 \\
\hline Phytolacca thyrsiflora Fenzl ex J.A. Sch. M. & 96296 & 66667 & 51852 & 59259 & 274074 & 68519 \\
\hline Phyllanthus niruri $\mathrm{L}$. & 155556 & 37037 & 22222 & 7407 & 222222 & 55556 \\
\hline Hydrocotyle cf. leucocephala Cham. e Sch. & 22222 & 170370 & 7407 & & 200000 & 50000 \\
\hline Não identificada 4 & 81481 & 51852 & 7407 & & 140741 & 35185 \\
\hline Solanum sp. & 44444 & 66667 & 14815 & 7407 & 133333 & 33333 \\
\hline Zanthoxyllum rhoifolium Lam. & 37037 & 59259 & 37037 & & 133333 & 33333 \\
\hline Não identificada 3 & 88889 & 14815 & 22222 & & 125926 & 31481 \\
\hline Tragia volubilis $\mathrm{L}$. & 66667 & 22222 & 7407 & 7407 & 96296 & 24074 \\
\hline Mimosa scabrella Benth. & 7407 & 37037 & & 22222 & 74074 & 18519 \\
\hline Myrsine ferruginea Sprengel & 37037 & 14815 & & & 51852 & 12963 \\
\hline Panicum sp. & 37037 & 7407 & & & 44444 & 11111 \\
\hline Tibouchina clinopodifolia (DC.) Cogn. & 22222 & & & 14815 & 37037 & 9259 \\
\hline Begonia cf. cucullata Willd. & 14815 & & & & 14815 & 3704 \\
\hline Sonchus asper (L.) Hill. & 7407 & & 7407 & & 14815 & 3704 \\
\hline Aegiphila sellowiana Cham. & 7407 & & & & 7407 & 1852 \\
\hline Mikania sp. & 7407 & & & & 7407 & 1852 \\
\hline Sonchus ciliatus Lam. & 7407 & & & & 7407 & 1852 \\
\hline Spigelia pusilla Mart. & & 7407 & & & 7407 & 1852 \\
\hline Total & 5688889 & 2111111 & 1118519 & 681481 & 9600000 & 2400000 \\
\hline
\end{tabular}

FLORESTA, Curitiba, PR, v. 41, n. 2, p. 335-346, abr./jun. 2011.

Souza, M. L. de; et al. 
Na tabela 3 constam os dados de frequências relativas das plântulas emergentes nas quatro parcelas do experimento.

Tabela 3. Frequências relativas (\%) das plântulas emergentes nas quatro parcelas do experimento.

Table 3. Relative frequencies (\%) of seedlings emerging in the four plots of the experiment.

\begin{tabular}{|c|c|c|c|c|c|c|}
\hline \multirow{2}{*}{ Espécie } & \multicolumn{6}{|c|}{ Frequências relativas } \\
\hline & Parc. 1 & Parc. 2 & Parc. 3 & Parc. 4 & Total & Média \\
\hline Cyperus sp. & 17,78 & 8,51 & 14,55 & 11,29 & 52,12 & 13,03 \\
\hline Senecio brasiliensis Less. Linnaea & 8,89 & 19,15 & 9,09 & 4,84 & 41,97 & 10,49 \\
\hline Não identificada 2 & 15,55 & 2,13 & 12,73 & 3,22 & 33,63 & 8,41 \\
\hline Gnaphalium sp. & 4,44 & 17,02 & 7,27 & 4,84 & 33,58 & 8,39 \\
\hline Phytolacca thyrsiflora Fenzl. ex. J.A. Sch. M. & 4,44 & 10,64 & 12,73 & 1,61 & 29,42 & 7,36 \\
\hline Zanthoxyllum rhoifolium Lam. & 6,67 & 14,89 & 1,82 & 3,22 & 26,60 & 6,65 \\
\hline Solanum sp. & 4,44 & 4,26 & 3,64 & 11,29 & 23,62 & 5,91 \\
\hline Não identificada 4 & 0,00 & 10,64 & 7,27 & 4,84 & 22,75 & 5,69 \\
\hline Phyllanthus niruri L. & 4,44 & 2,13 & 7,27 & 1,61 & 15,46 & 3,86 \\
\hline Pavonia sp. & 0,00 & 0,00 & 0,00 & 14,51 & 14,51 & 3,63 \\
\hline $\begin{array}{l}\text { Hydrocotyle cf. leucocephala Cham. e } \\
\text { Schlecht. }\end{array}$ & 6,67 & 0,00 & 5,45 & 1,61 & 13,73 & 3,43 \\
\hline Tragia volubilis $\mathrm{L}$. & 0,00 & 2,13 & 5,45 & 4,84 & 12,42 & 3,10 \\
\hline Borreria alata DC. & 2,22 & 2,13 & 0,00 & 8,06 & 12,41 & 3,10 \\
\hline Mimosa scabrella Benth. & 4,44 & 4,26 & 1,82 & 1,61 & 12,13 & 3,03 \\
\hline Não identificada 3 & 0,00 & 0,00 & 3,64 & 8,06 & 11,70 & 2,92 \\
\hline Myrsine ferruginea Sprengel & 6,67 & 0,00 & 1,82 & 1,61 & 10,10 & 2,52 \\
\hline Não identificada 1 & 6,67 & 0,00 & 1,82 & 1,61 & 10,10 & 2,52 \\
\hline Panicum sp. & 2,22 & 0,00 & 1,82 & 3,22 & 7,27 & 1,82 \\
\hline Tibouchina clinopodifolia (DC.) Cogn. & 2,22 & 0,00 & 0,00 & 3,22 & 5,45 & 1,36 \\
\hline Spigelia pusilla Mart. & 0,00 & 2,13 & 0,00 & 3,22 & 5,35 & 1,34 \\
\hline Sonchus asper (L.) Hill. & 0,00 & 0,00 & 1,82 & 1,61 & 3,43 & 0,86 \\
\hline Aegiphila sellowiana Cham. & 2,22 & 0,00 & 0,00 & 0,00 & 2,22 & 0,56 \\
\hline Begonia cf. cucullata Willd. & 0,00 & 0,00 & 0,00 & 1,61 & 1,61 & 0,40 \\
\hline Mikania sp. & 0,00 & 0,00 & 0,00 & 1,61 & 1,61 & 0,40 \\
\hline Sonchus ciliatus Lam. & 0,00 & 0,00 & 0,00 & 1,61 & 1,61 & 0,40 \\
\hline Total & 100,00 & 100,00 & 100,00 & 100,00 & 400,00 & 100,00 \\
\hline
\end{tabular}

Quanto à parcela 1, as espécies que apresentaram maiores frequências foram: Cyperus sp. (tiririca), com 17,8\%, e uma espécie não identificada 2 da família Poaceae, com 15,55\%. Em seguida tem-se a espécie Senecio brasiliensis Less. Linnaea (cravo-do-campo), com 8,89\%. Zanthoxyllum rhoifolium Lam., Hydrocotyle cf. leucocephala Cham. E Schlecht. (capitão), Myrsine ferruginea Sprengel e espécie não identificada 1 da família Poaceae, todas, juntas, apresentaram uma frequência de $6,67 \%$. As espécies Mimosa scabrella Benth. e Aegiphila sellowiana Cham. ocorreram com 4,44\% e 2,22\%, respectivamente.

$\mathrm{Na}$ parcela 2, a espécie Senecio brasiliensis Less. Linnaea apresentou uma frequência de 19,15\%. Gnaphalium sp. (macela) ficou com 17,02\%. A espécie Zanthoxyllum rhoifolium Lam. apresentou 14,89\%. Em seguida tem-se Phytolacca thyrsiflora Fenzl. Ex J.A. Schmidt Mart. (caruru) e a espécie não identificada 4 da família Asteraceae, ambas com frequência de 10,64\%. Em sexto lugar, temse a espécie Cyperus sp., com 8,51\%, e em último lugar tem-se as espécies Solanum sp. (joa-ti) e Mimosa scabrella Benth., com 4,26\% cada uma.

$\mathrm{Na}$ parcela 3, a espécie Cyperus sp. (tiririca) apareceu com uma frequência de 14,55\%. Em seguida tem-se a espécie não identificada 2, da família Poaceae, e Phytolacca thyrsiflora Fenzl. Ex J.A. Schmidt Mart. (caruru), ambas com 12,73\%. Zanthoxyllum rhoifolium Lam., Mimosa scabrella Benth. e Myrsine ferruginea Sprengel ocorreram com frequência baixa, 1,82\%.

$\mathrm{Na}$ parcela 4, a espécie Pavonia sp. (guanxuma) encontra-se com maior frequência, 14,51\%, seguida de Cyperus sp. (tiririca) e Solanum sp. (joa-ti), ambas com 11,29\%. Zanthoxyllum rhoifolium Lam. apareceu com 3,22\%, e as espécies Mimosa scabrella Benth, e Myrsine ferruginea Sprengel, 1,61\% cada uma. 
As espécies Cyperus sp. (tiririca) e Senecio brasiliensis Less. Linnaea (cravo-do-campo) são as espécies com melhor distribuição na área, apresentando frequência relativa média de 13,03\% e 10,49\%, respectivamente.

Pode-se observar que as espécies germinadas nesta parcela, onde outrora ocorreu lavoura, são, em sua maioria, pioneiras de porte herbáceo, sendo Cyperus sp., da família da Cyperaceae, aquela que possui o segundo maior número de indivíduos por hectare.

O juvevê, Zanthoxyllum rhoifolium Lam., encontra-se em sexto lugar, com uma frequência de 6,65\%. As espécies Mimosa scabrella Benth., Myrsine ferruginea Sprengel e Aegiphila sellowiana Cham. apresentaram frequências de 3,03\%,2,52\% e 0,56\%, respectivamente. Em último lugar quanto à distribuição na área de estudo, estão as seguintes espécies: Begonia cf. cucullata Willd. (begônia), Mikania sp. (cipó-cabeludo) e Sonchus ciliatus Lam. (serralha-lisa), com frequência de 0,40\%.

\section{Efeito da luminosidade na germinação das sementes}

$\mathrm{Na}$ casa de vegetação, as amostras de solo foram submetidas a duas condições distintas de luminosidade. Os resultados do efeito da luminosidade na germinação de sementes são reportados nas figuras 1 e 2. Para melhor visualização dos resultados, confeccionaram-se algumas figuras, esboçando-se o total de espécies germinadas com sombrite e sem sombrite.

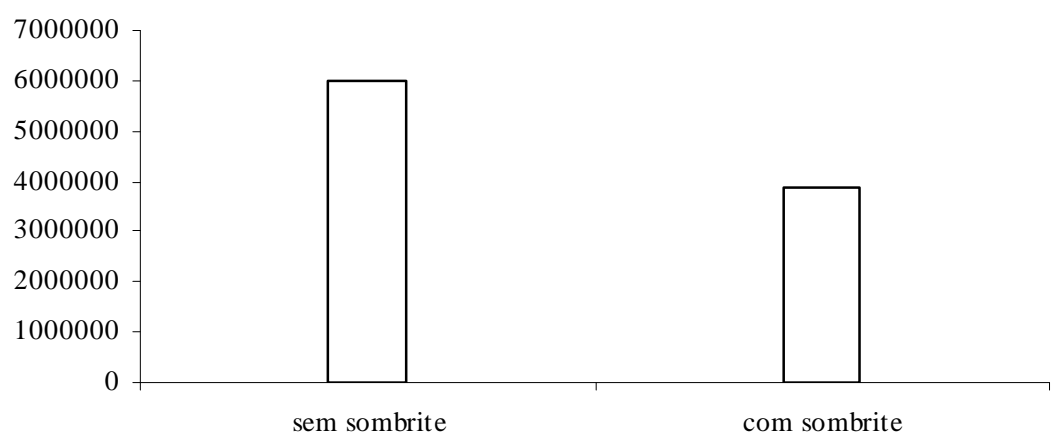

Figura 1. Número médio de sementes germinadas nas quatro profundidades das quatro parcelas nas duas condições de luminosidade.

Figure 1. Average number of seeds germinated in the four depths of the four plots in both lighting conditions.

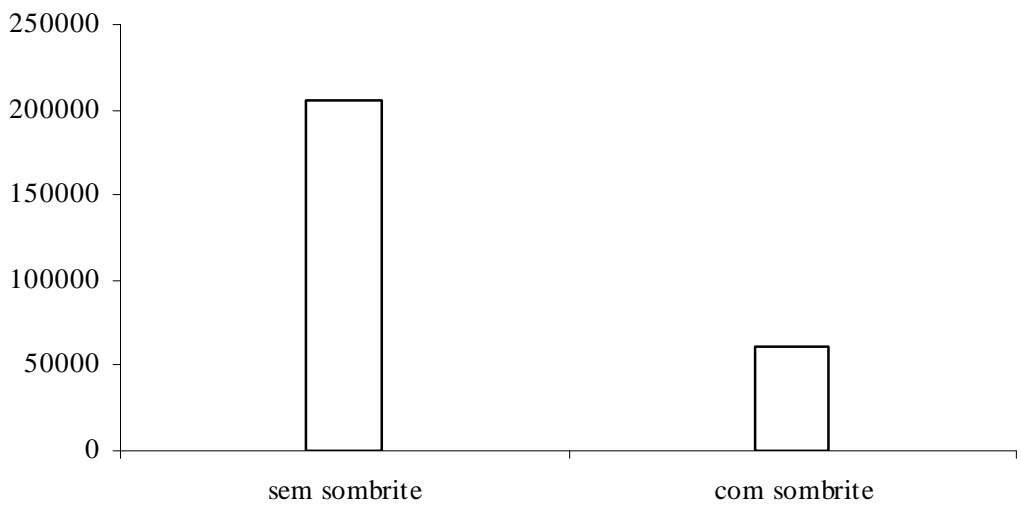

Figura 2. Número médio de sementes de espécies arbóreas germinadas nas quatro profundidades das quatro parcelas em estudo, sob as duas condições de luminosidade.

Figure 2. Average number of tree seeds germinated in the four depths of the four plots under study, under both lighting conditions. 
A figura 1 apresenta o número médio de sementes germinadas nas quatro profundidades das quatro parcelas nas duas condições de luminosidade. Observa-se uma ocorrência maior de espécies germinadas sem sombrite.

A figura 2 mostra o número médio de sementes de espécies arbóreas germinadas nas quatro profundidades das quatro parcelas em estudo, sob as duas condições de luminosidade. Observa-se uma tendência em ocorrer maior número de sementes germinadas sem sombrite.

\section{Avaliação da peneiragem das amostras de solo}

Na parcela 1, foram encontradas, através da técnica de peneiragem do solo, 7 sementes. Destas, 3 foram identificadas por meio de espécie, 1 de gênero e 3 de família. A densidade de Zanthoxyllum rhoifolium Lam. (juvevê) foi de 37.500 sementes/ha. Já a densidade de Campomanesia sp. (guabiroba) foi de 12.500 sementes/ha.

Na parcela 2, a triagem detectou 8 famílias botânicas, quais sejam: Rutaceae, Myrtaceae, Convolvulaceae, Malvaceae, Palmae, Sapindaceae, Anonnaceae e Fabaceae. Os destaques foram para as espécies Zanthoxyllum rhoifolium Lam. (com uma densidade de 25.000 sementes/ha) e Campomanesia sp. (com uma densidade de 125.000 sementes/ha).

Na parcela 3, foram encontradas 7 famílias botânicas, quais sejam: Leguminosae, Rutaceae, Poaceae, Aquifoliaceae, Rosaceae, Myrtaceae e Myrsinaceae. A família Leguminosae apresentou uma densidade de 425.000 sementes/ha, a família Rutaceae 200.000 sementes/ha e a família Poaceae 62.500 sementes/ha.

$\mathrm{Na}$ parcela 4, foram encontradas 4 famílias, quais sejam: Rutaceae, Poaceae, Rosaceae e Lauraceae. Destas, somente 3 foram identificadas em nível de espécie. A densidade da família Rutaceae foi de 75.000 sementes/ha, seguida da família Poaceae, com 87.500 sementes/ha.

A espécie não identificada 1, da família Leguminosae, apresentou 106.250 sementes por hectare, que é a maior média verificada. Em seguida, tem-se a espécie Zanthoxyllum rhoifolium Lam. (juvevê), com 84.375 sementes por hectare. Em quarto lugar vem a espécie Campomanesia sp. (guabiroba), com 34.375 sementes/ha.

\section{DISCUSSÃO}

O banco de sementes do solo do fragmento florestal estudado, em termos de espécies arbóreas com Araucaria angustifolia (Bert.) O. Ktze., parece ser pobre, pelo fato de ter sido detectado um considerável número de sementes de espécies de menor porte (gramíneas e herbáceas). Hall; Swaine (1980) verificaram que as sementes estocadas no solo são, em sua maioria, pertencentes a espécies pioneiras.

Uma razão de se encontrarem poucas espécies arbóreas e muitas espécies de menor porte no banco de sementes no solo desta área de estudo é, provavelmente, a pressão exercida por animais, já que esse fragmento florestal pode ter se transformado em um refúgio para a fauna. Devido ao fato de essa área ser um remanescente da vegetação natural na região, existe, pelos animais, uma considerável procura por sementes de espécies florestais, como é o caso das espécies Ocotea porosa (Nees.) L. Barroso (imbuia) e Araucaria angustifolia (Bert.) O. Ktze. (pinheiro-do-paraná). A fauna passa a exercer, em determinados períodos, uma pressão sobre o sistema, podendo, talvez, desencadear uma possível redução do estoque de sementes presentes na área.

Segundo Müller (1986), a diminuição cada vez maior das reservas florestais naturais faz com que as populações de roedores concentradas nessas áreas passem a buscar alimento nas áreas de culturas agrícolas circunvizinhas. No entanto, a carência de alimento ao final da safra agrícola, que geralmente coincide com a época de queda das sementes do pinheiro-do-paraná, leva os roedores a exercer um intenso consumo dessas sementes.

Além disso, o fato de aparecer um baixo número de sementes de espécies arbóreas no experimento poderia ser supostamente decorrente de problemas metodológicos na coleta de dados em nível de campo. Essa hipótese é pouco provável, haja vista que vários métodos alternativos foram testados simultaneamente, levando-se em consideração a possibilidade de restrições em cada metodologia individualmente no planejamento da amostragem. Outra possibilidade poderia estar relacionada com o período da coleta das amostras de solo e/ou também com o fato de ter sido realizada apenas uma amostragem durante o ano. 
O presente estudo constatou a ocorrência de quatro espécies arbóreas pioneiras e heliófilas presentes no banco de sementes: Mimosa scabrella Benth. (bracatinga); Myrsine ferruginea Sprengel (capororoca), Zanthoxyllum rhoifolium Lam. (juvevê) e Aegiphila sellowiana Cham. (pau-de-tamanco).

As espécies pioneiras e heliófilas apresentam um potencial para o processo de colonização de área perturbada, pois sua regeneração é possibilitada pela presença de suas sementes em estado de dormência no solo da floresta. Essas espécies, normalmente encontradas em clareiras nas florestas, tendem a germinar e se desenvolver melhor em condições de luz e a produzir grandes quantidades de sementes com grande capacidade de dispersão e/ou longevidade (BUDOWSKI, 1965; GOMEZ-POMPA, 1971).

Segundo Young et al. (1987), a eficiência de dispersão das sementes de espécies pioneiras lhes permite aptidão para colonizar florestas alteradas. As espécies constituintes dos estágios iniciais de colonização de uma área perturbada possuem uma série de características comuns, independentemente de suas afinidades taxonômicas, tais como eficientes mecanismos de dispersão e rápido crescimento.

Assim, essa constatação é semelhante à avaliação de Garwood (1989), em que se obteve maior quantidade de sementes presentes em solos agrícolas, pela ocorrência neles de maiores concentrações de espécies pioneiras. Dessa forma, a entrada de sementes oriunda de áreas vizinhas é um fator relevante.

Quanto à distribuição vertical de sementes no solo $(0-20 \mathrm{~cm})$ avaliada, pode-se perceber que a maior densidade de espécies se concentra de 0 a $10 \mathrm{~cm}$ de profundidade.

Observou-se que, tanto para as espécies herbáceas quanto para gramíneas e cipós, o número médio de sementes germinadas decresceu com a profundidade do solo. Para as espécies arbóreas, a situação foi um pouco diferente, pois foi na camada de 5 a $10 \mathrm{~cm}$ que houve maior número de sementes que germinaram, todavia também se manteve um certo padrão de decréscimo para as camadas seguintes.

Provavelmente, pequenas sementes podem ser encontradas em maiores profundidades no solo, podendo ser transportadas por lixiviação, pela atividade de minhocas, formigas e outros animais (tatu) e mesmo penetrar através de raízes podres. Segundo Young (1985), a presença de sementes abaixo de $20 \mathrm{~cm}$ de profundidade é o resultado da atividade de organismos vivos, resultando no transporte ascendente e descendente dessas sementes.

Para esse autor, as sementes enterradas em maiores profundidades no solo tendem a permanecer dormentes por longo período de tempo, sendo que somente poucas delas têm chances de germinar.

Quanto à influência do nível de sombreamento sobre a germinação das sementes, a maioria das espécies encontradas no banco de sementes foi favorecida pela maior luminosidade.

Leal Filho (1992) constatou que todas as espécies pioneiras, arbóreas ou não, encontradas no banco de sementes germinaram na condição de maior luminosidade.

No trabalho de Hall; Swaine (1980), na Floresta Natural de Gana, onde foram testados níveis diferentes de iluminação sobre a germinação das sementes presentes no solo da floresta, os resultados mostraram que o número total de sementes, assim como o número de sementes de espécies arbóreas pioneiras germinadas, foi maior sob $0 \%$ de sombreamento.

Observou-se uma tendência maior de germinação de sementes de cipós sob 50\% de sombreamento. Possivelmente, essas espécies são tolerantes ao sombreamento. A luz é um dos mais importantes fatores ambientais responsáveis pela superação da dormência de sementes de muitas plantas (FELIPPE; KLEIN, 1991).

As espécies herbáceas e de gramíneas apresentam uma grande plasticidade em relação à sensibilidade à luz. A maioria é indiferente à luz, podendo germinar em qualquer condição luminosa (POLO; FELIPPE, 1983).

A espécie Araucaria angustifolia (Bert.) O. Ktze. (pinheiro-do-paraná) não foi observada no banco de sementes no solo. Possivelmente, essa espécie não forma banco de sementes, por dois motivos: um, devido à pressão tanto da fauna como do homem sobre suas sementes; outro, devido a essa espécie possuir sementes recalcitrantes, as quais perdem o poder germinativo rapidamente. Essa ausência pode ainda estar relacionada com o período da coleta das amostras de solos.

\section{CONCLUSÕES}

De acordos com os resultados obtidos nas condições em que foi desenvolvido o presente trabalho, pode-se concluir:

- O banco de sementes de espécies arbóreas pode ser considerado pobre, ao contrário do banco de sementes de espécies e herbáceas. 
- As espécies arbóreas ocorrentes no banco de sementes no solo foram: Myrsine ferruginea Sprengel (capororoca), Zanthoxyllum rhoifolium Lam. (juvevê), Mimosa scabrella Benth. (bracatinga) e Aegiphila sellowiana Cham. (pau-de-tamanco).

- Tanto para as espécies herbáceas quanto para gramíneas e cipós o número médio de sementes germinadas (por hectare) decresceu com a profundidade do solo. Houve maior número de sementes germinadas de espécies arbóreas na camada de 5 a $10 \mathrm{~cm}$.

- Em todas as profundidades, o número médio de sementes germinadas (por hectare) de espécies herbáceas, gramíneas e arbóreas foi maior sob $0 \%$ de sombreamento, enquanto que para o cipó foi maior sob $50 \%$ de sombreamento.

- Os experimentos não comprovaram a hipótese inicial do estudo, de que no fragmento estudado a regeneração ocorre através do banco de sementes no solo, pelo menos no que se refere ao tempo de duração do experimento na casa de vegetação. Diante disso, as próximas hipóteses que poderiam vir a ser avaliadas são: a) a regeneração através do banco de sementes requer um intervalo de tempo maior; b) a regeneração nesse fragmento ocorreria através do banco de plântulas.

- Provavelmente, a estratégia de regeneração da maioria das espécies presentes nesta área de estudo parece não se dar pelo banco de sementes no solo, conforme a nossa hipótese.

\section{REFERÊNCIAS}

ABDULHADI, R. Soil seed banks of weeds and other species in a rain forest community, Asian Pacific Weed Science, p. 215 - 223, 1991.

BASKIN, C. C.; BASKIN, J. M. Physiology of dormancy and germination in relation to seed bank ecology. In: LECK, M. A. Ecology of soil seed banks, San Diego: Academic Press, 1989. 461 p.

BERG, R. Y. Plant distribution as seen from plant dispersal: general principles and basic modes of plant dispersal, Sonderbd. Naturwiss. Ver. Hamburg, n. 7, p. 13 - 16, 1983.

BUDOWSKI, G. Distribution of tropical American rain forest species in the light of succession processes, Turrialba, v. 15, n. 1, p. 40 - 42, 1965.

CHEKE, A. S.; NANAKORN, W.; YANKOSES, C. Dormancy and dispersal of seeds of secondary forest species under the canopy of tropical rain forest in northern Tailand, Biotropica, v. 11, n. 2, p. 88 - 95, 1979.

DANTAS, M. Germination of species from the soil seed bank. In: Studies in succession in cleared areas of Amazonian Rain Forest, Oxford: Linacre College, p. 233 - 240, 1989.

FENNER, M. Seed ecology. New York: Chapman and Hall, 1985, 150 p.

FELIPPE, M.; KLEIN, A. Efeito da luz na germinação de sementes de ervas invasoras, Pesq. Agropec. Bras. Brasília, v. 26, n. 7, p. 9 55- 966, 1991.

GARWOOD, N. C. Tropical soil seed banks: a review. In: LECK, M. A. Ecology of soil seed banks, San Diego: Academic Press, 1989, p. 149 - 204.

GENTRY, A. H. Dispersal ecology and diversity in Neotropical Forest Communities, Sonderbd. Naturwiss. Ver. Hamburg, n. 7, p. 303 - 314, 1983.

GÓMEZ-POMPA, A. Posible papel de la vegetación secundaria em la evolución de la flora tropical, Biotropica, v. 3, n. 2, p. 125 - 135, 1971.

HALL, J. B.; SWAINE, M. D. Seed stocks in Ghanaian Forest Soils, Biotropica, v. 12, n. 4, p. 256 - 263 , 1980.

HOLTHUIJZEN, A. M. A.; BOERBOOM, J. H. A. The Cecropia seedbank in the Surinam Lowland Rain Forest, Biotropica, v. 14, n. 1, p. 62 - 68, 1982.

LAMPRECHT, H. Silvicultura nos trópicos: ecossistemas florestais e respectivas espécies arbóreas possibilidades e métodos de aproveitamento sustentado (Waldbau in den tropen). Rossdorf: TZ-Verl. Ges., (GTZ), República Federal da Alemanha, 1990. 343 p. 
LEAL FILHO, N. Caracterização do banco de sementes de três estádios de uma sucessão vegetal na Zona da Mata de Minas Gerais. 116 f. Dissertação (Mestrado em Engenharia Florestal) - Universidade Federal de Viçosa, Viçosa, 1992.

LONGHI, S. J. A estrutura de uma floresta natural de Araucária angustifolia (Bert.) O. Ktze, no sul do Brasil. 198 f. Dissertação (Mestrado em Engenharia Florestal) - Setor de Ciências Agrárias, Universidade Federal do Paraná, 1980.

MAACK, G. Geografia física do Estado do Paraná. Curitiba: CODEPAR, 1968. 350 p.

METIVIER, J. R. Dormência e germinação. In: FERRI, M. G. Fisiologia vegetal. São Paulo: Ed. Pedagógica e Universitária, 1986, n. 2, 392 p.

MÜLLER, J. A. A influência dos roedores e aves na regeneração da Araucaria angustifolia (Bert.) 0. Ktze. 65 f. Dissertação (Mestrado em Engenharia Florestal) - Setor de Ciências Agrárias, Universidade Federal do Paraná, 1986.

POLO, M.; FELIPPE, G. M. Germinação de ervas invasoras: efeito de luz e escarificação. Revista Brasileira de Botânica, n. 6, p. 55 - 60, 1983.

RICO-GRAY, V.; GARCIA-FRANCO, J. G. Vegetation and soil seed bank of succession stages in tropical lowland deciduous Forest, Journal of Vegetation Science, México, v. 3, p. 617 - 624, 1982.

ROBERTS, H. A.; FEAST, P. M. Fate of seeds of some annual weeds in different depths of cultivated and undisturbed soil. Weed Research, Oxford, v. 12, n. 5, p. 316 - 324, 1972.

VELOSO, H. P.; RANGEL FILHO, A. L. R.; LIMA, J. C. A. Classificação da vegetação brasileira, adaptada a um sistema universal IBGE. Rio de Janeiro, 1991, 123 p.

YOUNG, K. R. Deeply buried seeds in a Tropical Wet Forest in Costa Rica, Biotropica, v. 17, n. 4, p. $336-338,1985$.

YOUNG, K. R.; EWEL, J. J.; BROWN, B. J. Seed dynamics during forest succession in Costa Rica, Vegetatio, v. 71, p. 157 - 173, 1987. 
FLORESTA, Curitiba, PR, v. 41, n. 2, p. 335-346, abr./jun. 2011

Souza, M. L. de; et al. 